\title{
Patients with Chronic Urticaria Remain Largely Undertreated: Results from the DERMLINE Online Survey
}

\author{
Nicola Wagner · Alexander Zink · Katharina Hell • Maximilian Reinhardt • \\ Katrin Romer · Elena Hillmann · Daniel Baeumer · Maximilian C. Schielein
}

Received: February 25, 2021 / Accepted: April 16, 2021 / Published online: May 4, 2021

(C) The Author(s) 2021

\begin{abstract}
Introduction: Chronic urticaria (CU) is an unpredictable disease, with high disease burden and a significant negative impact on quality of life, especially in patients of working age. Many patients are undertreated, and there is poor awareness of strategies to manage patients with $\mathrm{CU}$ in the real-world setting. The current study aimed to gain a better understanding of $\mathrm{CU}$ from the patients' perspective, including the body areas most affected by wheals and angioedema, the disease burden and current use of the healthcare system.
\end{abstract}

Supplementary Information The online version contains supplementary material available at https:// doi.org/10.1007/s13555-021-00537-5.

N. Wagner $(\bowtie)$

Department of Dermatology, University Hospital Erlangen, Friedrich-Alexander-Universität ErlangenNürnberg (FAU), Erlangen, Germany e-mail: Nicola.Wagner@uk-erlangen.de

A. Zink · K. Hell · M. C. Schielein

Department of Dermatology and Allergy, School of Medicine, Technical University of Munich, Munich, Germany

\section{K. Hell}

Institute for Medical Information Processing, Biometry and Epidemiology (IBE), Ludwig

Maximilian University (LMU), Munich, Germany

M. Reinhardt · K. Romer · E. Hillmann - D. Baeumer Novartis Pharma GmbH, Nuremberg, Germany
Methods: A nationwide online survey was performed in Germany involving individuals who reported a diagnosis of $\mathrm{CU}$ and experienced symptoms within 3 months prior to inclusion.

Results: This self-report survey included 1037 participants $(89.2 \%$ female), with a mean $\pm s$ tandard deviation (SD) age of $33.4 \pm 11.0$ years and a mean \pm SD disease duration of $10.0 \pm 9.4$ years. On average, participants suffered from urticaria symptoms for $3.0 \pm 4.3$ years before diagnosis. In $73 \%$ of participants, symptoms worsened due to external factors, with the majority specifying stress in their personal life or work-related stress as eliciting factors. Within the previous 3 months, 87.4 and $44.1 \%$ of participants experienced wheals and angioedema, respectively, at multiple body areas, and most (79.6\%) participants had uncontrolled symptoms as measured with the Urticaria Control Test. Despite the high burden of disease, $60.3 \%$ of participants stated that they were not currently receiving treatment. The most commonly used therapies to treat CU were oral $(72.8 \%)$ and non-prescription $(43.3 \%)$ and prescription $(47.3 \%)$ topical drugs, with $18.0 \%$ of the participants receiving injectable/infused drugs.

Conclusion: The majority of the participants responding to the survey reported that $\mathrm{CU}$ is not sufficiently controlled, thereby severely influencing a highly productive time in their life. The body areas most affected by wheals and angioedema are specified, based on data 
provided by a large group of affected participants. A greater awareness of disease burden and available treatment options is needed.

Keywords: Chronic urticaria; Treatment; Patient satisfaction; Undertreated; Urticaria control test; Angioedema; Online survey; Distribution urticaria

\section{Key Summary Points}

Data obtained in our online survey describe the real-world perception of afflicted individuals in terms of their satisfaction with treatment and disease control of urticaria symptoms.

Responses to the survey questionnaire have to be interpreted with care, as bias regarding gender, age, accessability to internet/social network platform, selfreport of diagnosis and possible interference with dissatisfaction has to be taken into account.

Summarizing the data, afflicted individuals complain about insufficient disease control with a high impact on their quality of life.

Awareness of urticaria and its treatment options is needed in order to address patients who have been abandoned or do not seek medical advice.

\section{DIGITAL FEATURES}

This article is published with digital features, including a summary slide, to facilitate understanding of the article. To view digital features for this article go to https://doi.org/10.6084/ m9.figshare.14381798.

\section{INTRODUCTION}

Chronic urticaria (CU) is a skin disorder characterized by the repeated occurrence of wheals or hives with or without angioedema, for more than 6 weeks $[1,2]$. It is an unpredictable, debilitating disease with high disease burden and has a significant negative impact on the quality of life (QoL) of those affected [1]. CU can result in work productivity impairment and absenteeism [3], interference with sleep and daily activities [4] and high levels of anxiety and psychological distress [5-7]. Moreover, the unpredictable nature of CU-associated angioedema, characterized by sudden swelling of the dermis, subcutaneous tissue or submucosa, can cause a fear of experiencing a life-threatening episode [8]. Alarmingly, angioedema is experienced in up to $40 \%$ of patients with urticaria [9], and coexistence of angioedema and wheals is experienced by up to $67 \%$ of patients [8]. As such, the EAACI/GA ${ }^{2}$ LEN/EDF/WAO guidelines for the treatment of urticaria recommend a specific algorithm with treatment escalation until complete symptom control is achieved [2].

A worldwide, observational study on $\mathrm{CU}$ in the real-world setting (the "AWARE" study) revealed that patients with $\mathrm{H}_{1}$-antihistaminerefractory chronic spontaneous urticaria have high rates of uncontrolled disease, angioedema, comorbid chronic inducible urticaria (CIndU), are undertreated, have impaired QoL and rely heavily on healthcare resources [10]. Indeed, numerous global reports have highlighted that patients with CSU are undertreated and are not receiving the recommended therapy $[4,11,12]$, thus emphasizing the need for greater awareness and adherence to international guidelines. The aim of the online survey (DERMLINE) reported here is to investigate the burden of $\mathrm{CU}$ solely from the individual's perspective, with the objective of highlighting important unmet clinical needs in Germany. This self-report survey also aims to provide insights into the disease burden of $\mathrm{CU}$, the use of medical care and the body areas most affected by angioedema and wheals, as reported by respondents to the questionnaire. 


\section{METHODS}

\section{Participants}

The DERMLINE online survey recruited participants in Germany purely through online banner advertising, targeting individuals who are highly active on Facebook and Google. The banner ads stated one of the following: 'Do you have urticaria? Participate in an online survey now'; 'Urticaria survey-participate now'; or 'Urticaria-looking for participants in a survey.' The protocol was designed to capture participants of a specific population afflicted with urticaria, namely individuals who had mostly physician-diagnosed urticaria. The survey aimed to exclude individuals who did not have a validated urticaria diagnosis, and the protocol included a detailed analysis plan.

The aim of this study was to obtain self-reported data on the real-life impact of $\mathrm{CU}$ and the current use of the healthcare system in Germany by patients with CU. Between 20 December 2018 and 25 January 2019, participants were invited to complete a survey that consisted of a maximum of 57 questions (depending on how the questions were answered) designed by experienced physicians specialized in treating urticaria patients (for survey questions, see Electronic Supplementary Material [ESM] S1). All answers were self-reported by the participant. Inclusion criteria for participation were a prior diagnosis of $\mathrm{CU}$ by a physician and the presence of symptoms within the 3 months prior to inclusion in the survey.

Implausible datasets (if age was less than the time to diagnosis plus the time since diagnosis) were excluded from the analysis, noting that some participants had difficulties in distinguishing between onset and time to diagnosis; however, most of these checks were already built into the survey to reduce bias.

\section{Compliance with Ethics Guidelines}

The study was notified retrospectively to the local ethics committee of the University of Erlangen. The study is exempt from institutional review board approval in line with national legislation in Germany. This study was performed in accordance with the Helsinki Declaration of 1964 and its later amendments. Participants provided consent to participate and data evaluation was performed anonymously.

\section{Survey Design}

A literature search was performed to identify reasons why individuals with different diseases do not visit a doctor and to define questions surrounding this topic, from which the authors of this study generated questions. Questions addressing other dermatological diseases were also included. The different thematic groups of the survey included: demographics; disease characteristics; body area analysis of symptoms; impact on daily life; emotional burden; disease control as measured by the Urticaria Control Test (UCT); current and previous treatments; and use of and satisfaction with medical care and treatment. The UCT retrospectively assesses disease control over the previous 4 weeks; if participants have a score of $\geq 12$ points (range $0-16)$, urticaria is considered to be controlled [13].

\section{Data and Statistics}

Data are reported as observed and were analyzed using IBM SPSS Statistics (version 25; IBM Corp., Armonk, NY, USA). In terms of descriptive statistics, the evaluation of each question included age and gender to show a comparison throughout the whole population. The mean, standard deviation (SD), absolute number and percentage are provided. Data and statistics were analyzed anonymously by a third party.

\section{RESULTS}

\section{Demographics and Disease Characteristics}

Overall, over a 37-day period 6375 people visited the online landing page and 2422 (38\%) individuals clicked on the survey link. Of these, 1385 (22\%) were excluded because they did not meet the inclusion criteria or did not complete 
the survey; ultimately, 1037 (16\%) participants with physician-diagnosed $\mathrm{CU}$ completed the online survey and were included in this analysis. Figure 1 shows the reasons for exclusions. In terms of geography, participants were distributed equally throughout Germany.

The mean $( \pm$ SD) age of participants was 33.4 \pm 11.0 (range 18-67) years, and the majority were female $(89.2 \%$; 925/1037; Table 1$)$. The mean disease duration was $10.0 \pm 9.3$ years $(n=1006)$, although $34.9 \% \quad(351 / 1006)$ of affected individuals reported having CU symptoms for $>10$ (range of 1-53) years. On average, participants suffered from urticaria for $3.0 \pm 4.3$ years prior to receiving a diagnosis. Within the previous 3 months, $86.3 \% \quad(895 / 1037)$ of patients experienced wheals and 43.1\% (447/ 1037) experienced angioedema across multiple body areas. The mean UCT score was 7.9 $( \pm 3.9)$, with $79.6 \%(825 / 1037)$ of participants having a UCT score $<12$, indicating that their symptoms were not well controlled during the previous 4 weeks.

Participants reported that the body areas most affected by wheals were arms (80.3\%; $719 / 895)$, legs (73.5\%; 658/895), hands/fingers (66.4\%; 594/895) and breast/abdomen (65.4\%; 585/895; Fig. 2a). Angioedema occurred most often on the hands/fingers $(62.2 \% ; 278 / 447)$,

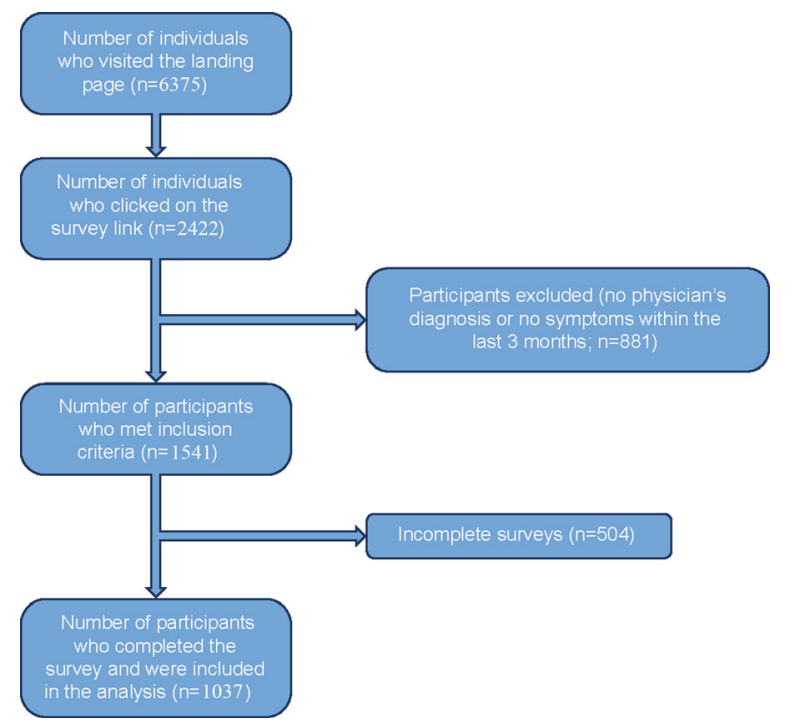

Fig. 1 Flow diagram showing the inclusion and exclusion of participants into the DERMLINE survey feet $(54.8 \% ; 245 / 447)$, head $(51.5 \% ; 230 / 447)$, arms $(50.8 \% ; 227 / 447)$ and legs (49.9\%; 223/447; Fig. 2b). The genitals or anal area were also affected by wheals $(15.2 \% ; 136 / 895)$ and angioedema (12.3\%; 55/447). Many participants felt that their $\mathrm{CU}$ symptoms were worsened by external factors (Fig. 2c), with the main triggers being stress in the participants' personal lives $(68.5 \% ; 522 / 762)$ and work-related stress (63.3\%; 482/762).

\section{Influence of Disease Activity on Daily Living}

More than half of the participants (51.9\%; 538/1037) avoided stressful situations in fear of triggering symptoms of their disease (Fig. 3a), often feeling depressed, sad, emotionally worn down or hopeless within the last month $(67.5 \%$; 700/1037), and stating that they took considerably less pleasure in activities they normally liked doing (55.8\%; 579/1037; Fig. 3b). Participants had also modified their diet (42.1\%; $437 / 1037)$, reduced their sporting activities $(33.1 \% ; 343 / 1037)$ and socialized less frequently $(19.8 \% ; 205 / 1037)$ due to their disease (Fig. 3a).

\section{Healthcare Utilization of Participants}

The survey revealed that most participants currently under treatment were seeing a dermatologist $(64.6 \% ; 271 / 412)$ and/or a general practitioner $(42.7 \% ; 176 / 412)$; few currently under treatment were being treated in an outpatient department $(15.0 \%$; 62/412) or specialized urticaria center $(6.8 \% ; 28 / 412$; Fig. $4 a)$. Throughout their disease, most participants had previously seen a dermatologist (80.8\%; $557 / 689)$ and/or a general practitioner (67.6\%; 466/689) due to their CU symptoms. Participants had been treated at several different centers, and many were unsatisfied with their treatment (ESM Fig. 1). Those individuals not currently seeing a physician $(60.3 \% ; 625 / 1037)$ stated that they had adapted to their disease and could cope with it $(50.8 \% ; 316 / 622)$, it was too long to wait for a physician's appointment $(34.4 \% ; 214 / 622)$ or that they had no symptoms when visiting their physician $(31.2 \% ; 194 / 622)$. 
Table 1 Demographics for all 1037 participants included in the DERMLINE survey

\section{Characteristic}

Demographics

Female gender, $n$ (\%)

Age (years) ${ }^{a}$, mean $\pm S D$

Disease characteristics, mean \pm SD

Duration of disease (years) ${ }^{a}$

Time to diagnosis (years) ${ }^{\mathrm{a}}$

Time since diagnosis (years) ${ }^{a}$

Age at disease onset (years) ${ }^{a}$

Age at disease diagnosis (years) ${ }^{a}$

Treatment status, $n$ (\%)

Currently treated

Previously treated

Never treated

Urticaria triggers, $n(\%)$

Spontaneous

Known factors

Both spontaneous and known factors

CU symptoms within the previous 3 months, $n$ (\%)

Pruritus

Wheals

Angioedema

Others

Urticaria control test (UCT)

UCT score, mean \pm SD

Urticaria controlled (UCT $\geq 12$ ), $n$ (\%)

Urticaria uncontrolled (UCT < 12), $n(\%)$
Participants $(N=1037)$

$925(89.2 \%)$

$33.4 \pm 11.0$

$10.0 \pm 9.3$

$3.0 \pm 4.3$

$7.0 \pm 7.9$

$23.5 \pm 12.5$

$26.5 \pm 12.0$

$412(39.7 \%)$

$689(66.5 \%)^{\mathrm{b}}$

$194(18.7 \%)^{\mathrm{b}}$

$296(28.5 \%)$

$297(28.6 \%)$

$444(42.8 \%)$

$947(91.3 \%)$

$895(86.3 \%)$

$447(43.1 \%)$

$157(15.1 \%)$

$7.9 \pm 3.9$

$212(20.4 \%)$

$825(79.6 \%)$

$C U$ Chronic urticaria, $S D$ standard deviation

a $N=1006,31$ participants (3.0\%) were removed from analysis due to implausibility

b $N=1036,1$ participant was removed from analysis due to implausibility (a yes or no answer missing for the question, "have you ever been treated in the past?") 
(a) Wheals $(\mathrm{n}=895)$

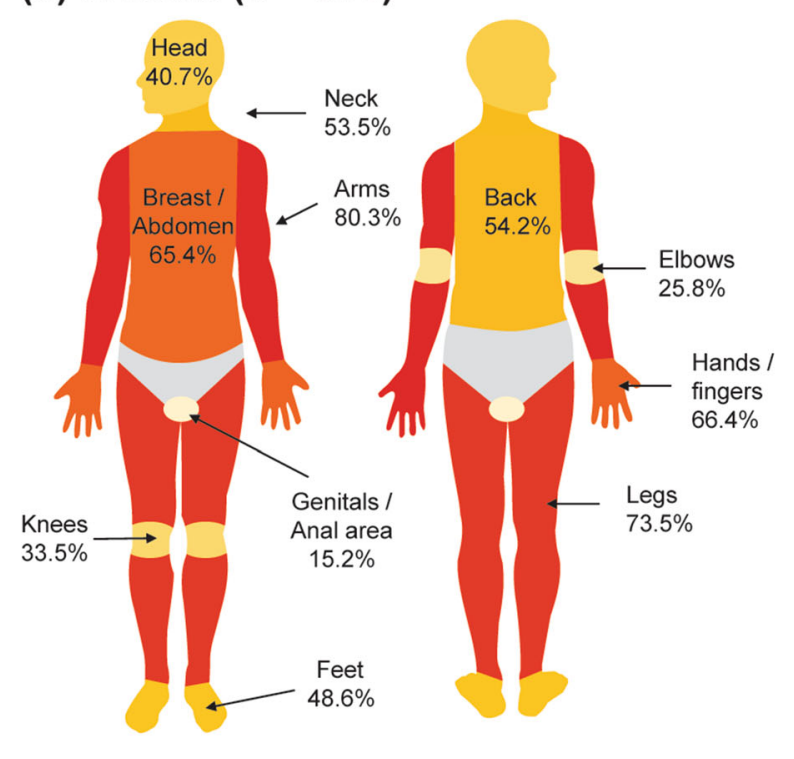

(b) Angioedema ( $n=447)$

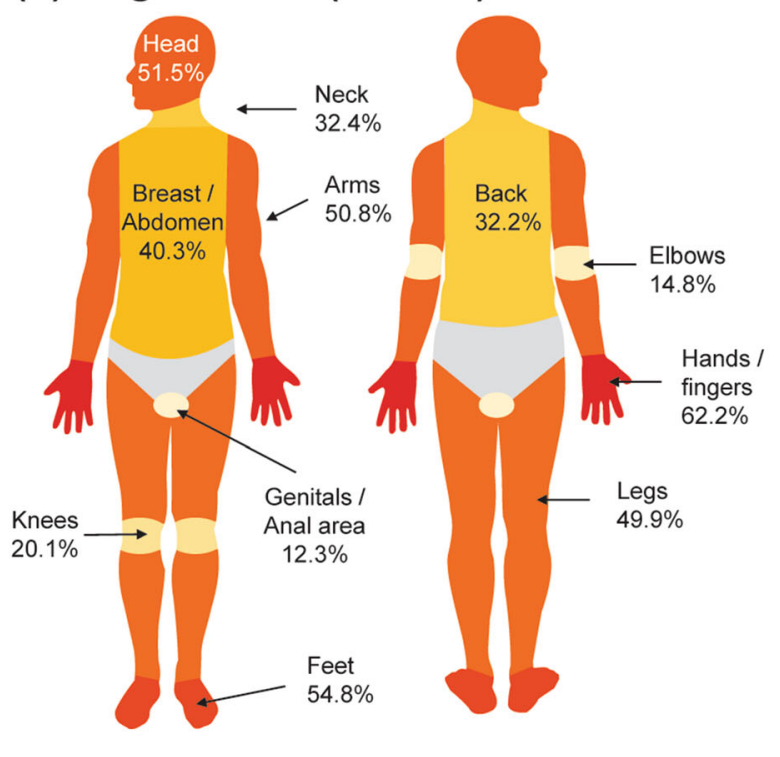

(c)

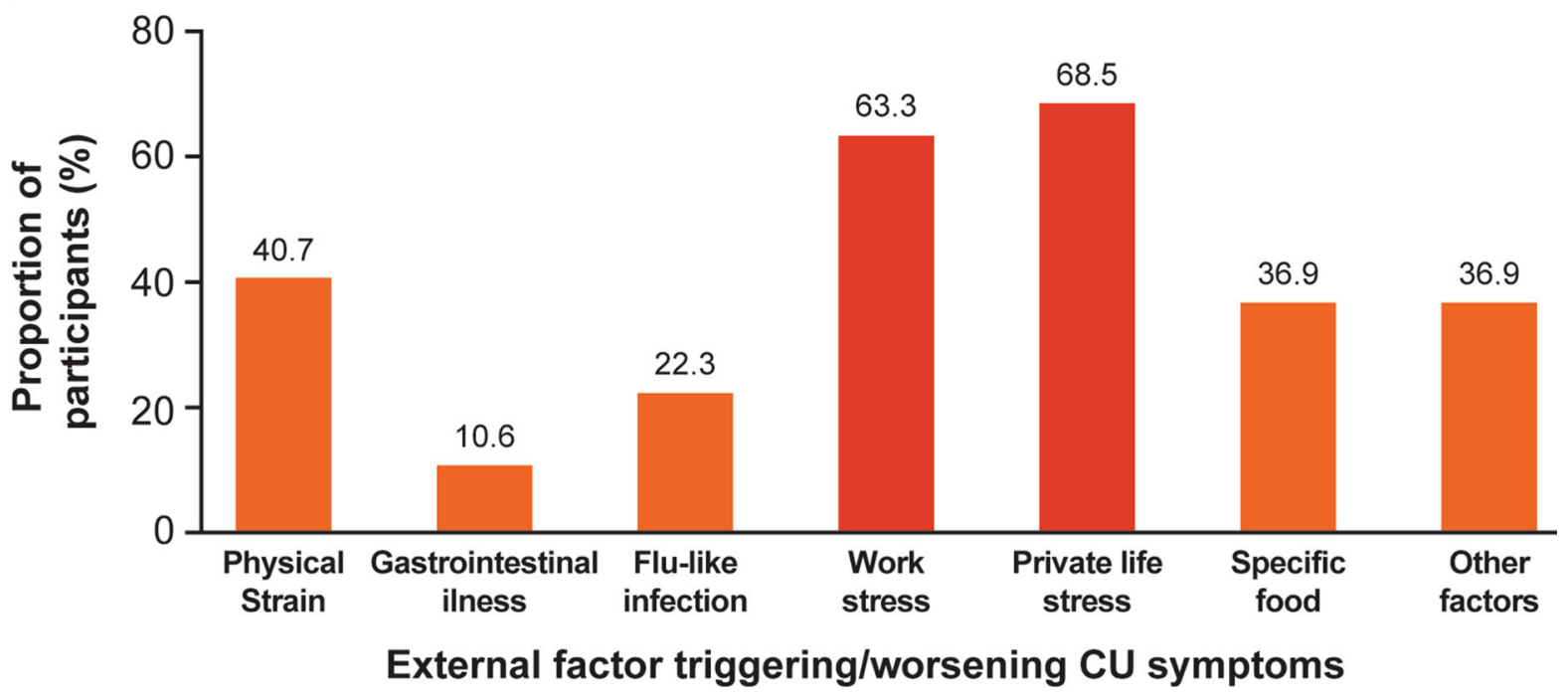

Fig. 2 In the survey, participants were asked, "On which parts of your body do wheals mainly occur?” $(n=895 ; \mathbf{a})$; "On which parts of the body do hives (angioedema) mainly occur?" ( $n=447 ; \mathbf{b})$; and, "Which of the following external factors make your hives worse: physical strain,

\section{Current Treatment and Participant Satisfaction}

Participants most commonly used oral (73.0\%; 750/1027) and topical (47.6\%; 489/1027) prescriptions; $43.2 \%$ (444/1027) used non- gastrointestinal illness, flu-like infection, work stress, private life stress, specific food, or other factors?" $(n=762 ; \mathbf{c})$. Percentages were calculated for each question from the total number of responders

prescription (as many participants do not visit a physician) treatments (Fig. 4b); 18.2\% received injectable/infused drugs. In total, 22.6\% (120/ 531) of participants felt that their previous treatment did not help, but that their current one does; $62.7 \% \quad(333 / 531)$ indicated that 
(a)

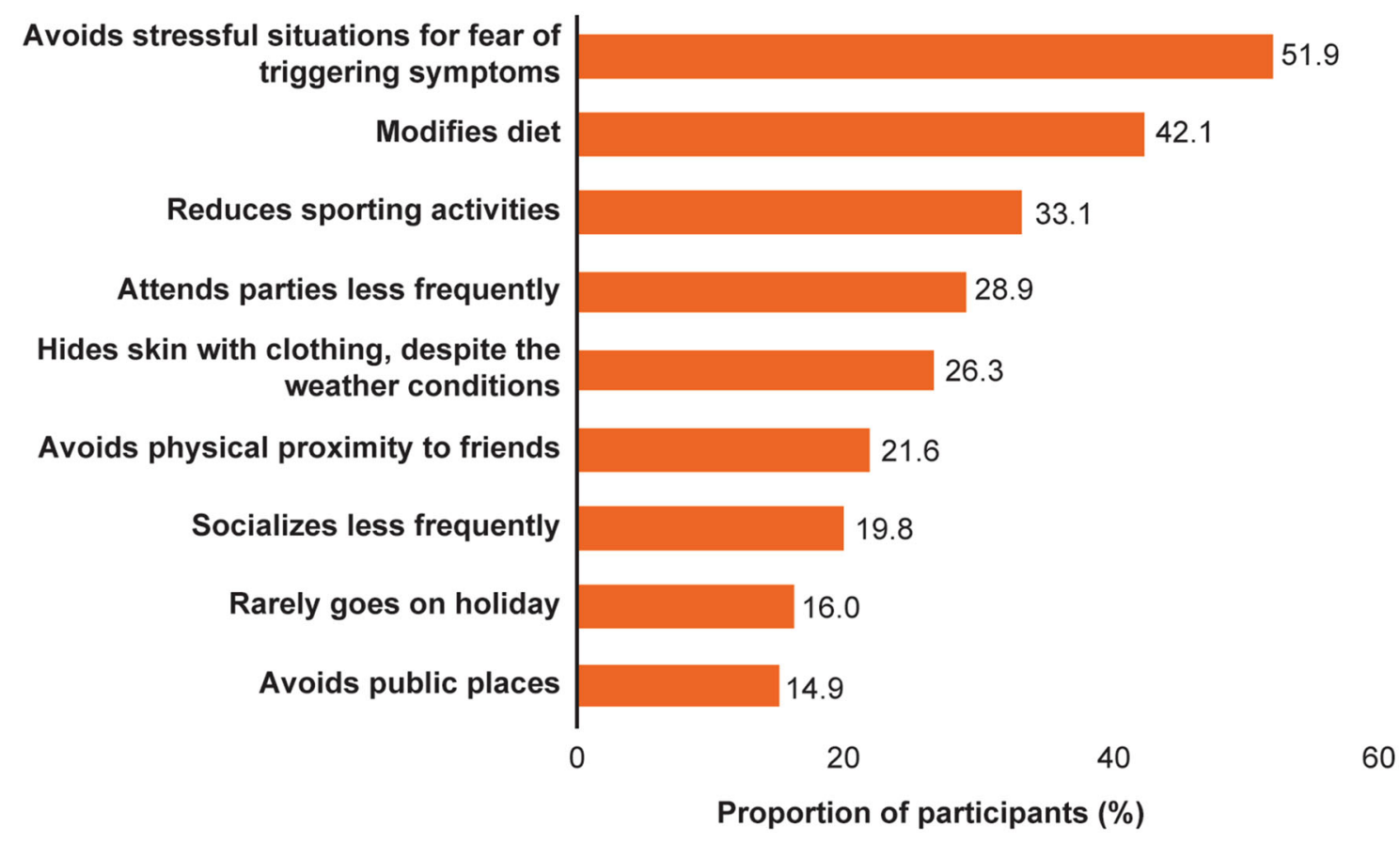

(b)

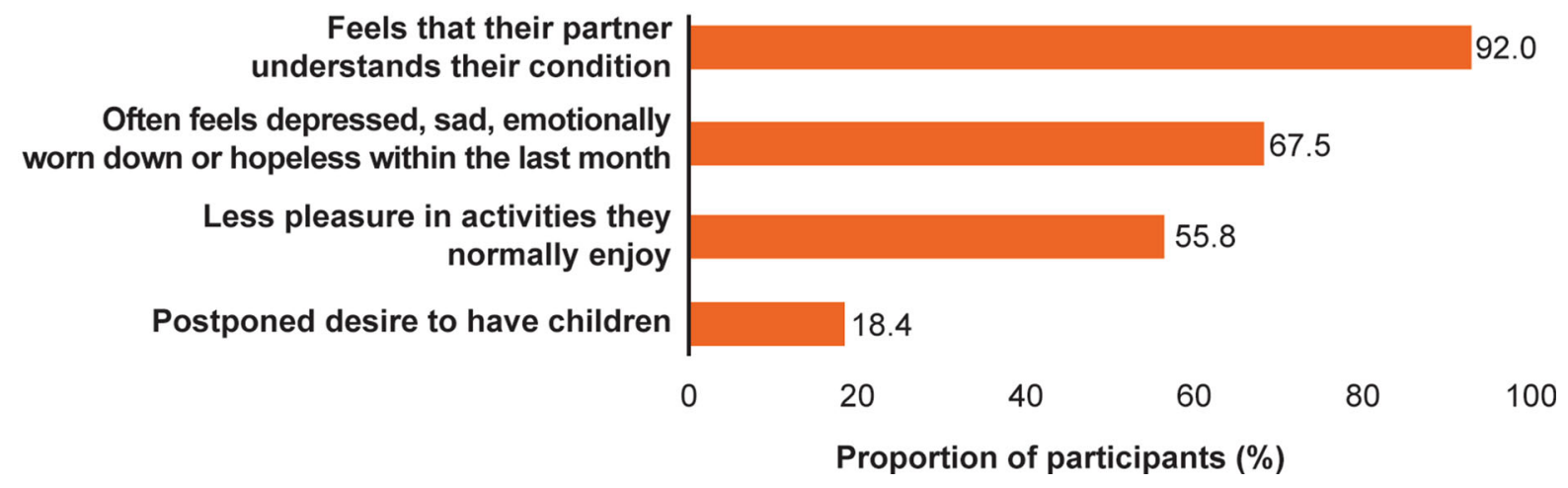

Fig. 3 In the survey, participants $(n=1037)$ were asked about the impact of urticaria and about how they have adapted their lifestyle (a), and the impact of urticaria on

previous treatment(s) did not help and they were currently not under any treatment for urticaria. Fewer than half $(48.8 \%)$ of the participants were satisfied or very satisfied with their treatment (Fig. 4c), and $52.8 \%$ of participants currently receiving treatment felt like their medication did not help (Fig. 5). their emotions and desires (b), using the pre-specified answers shown in the graphs

\section{DISCUSSION}

The findings of our patient-reported survey provide valuable insights into the self-reported distribution of urticaria symptoms and angioedema on different body areas in individuals suffering from urticaria in Germany, as also shown in a cross-sectional epidemiology study [14]. Furthermore, the disease burden of CU, the use of medical care and participants' 
(a)

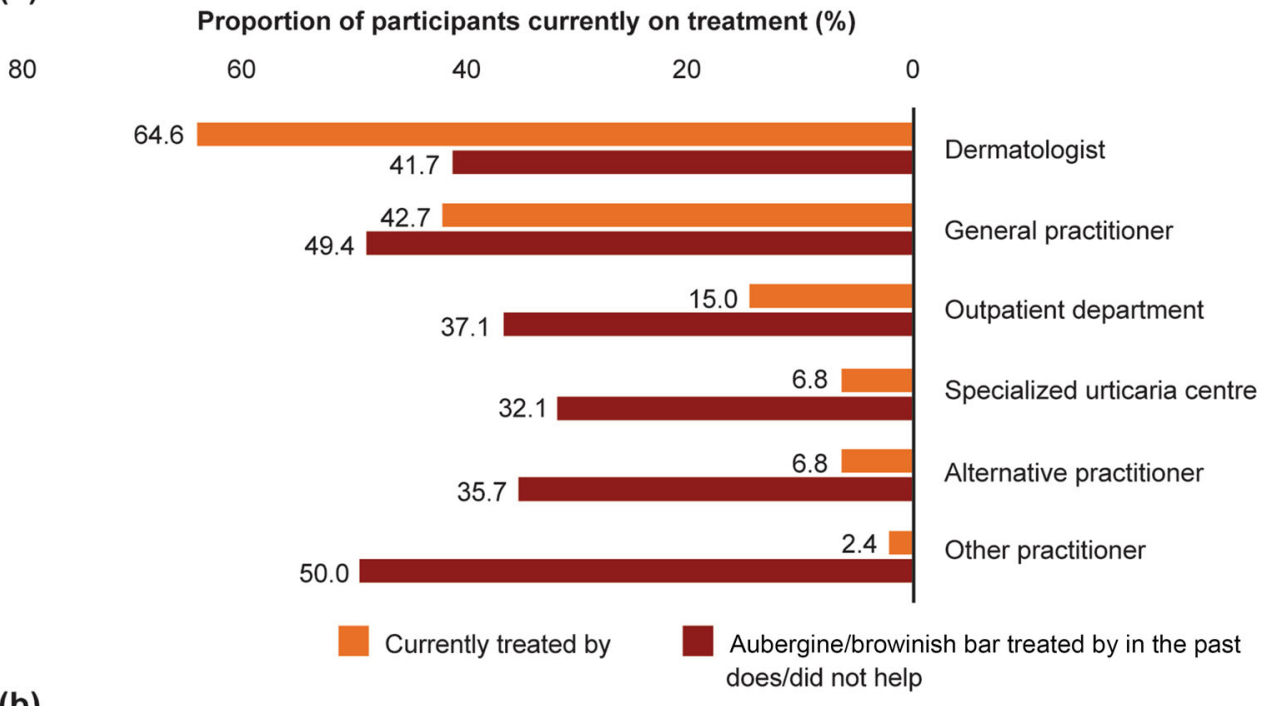

(b)

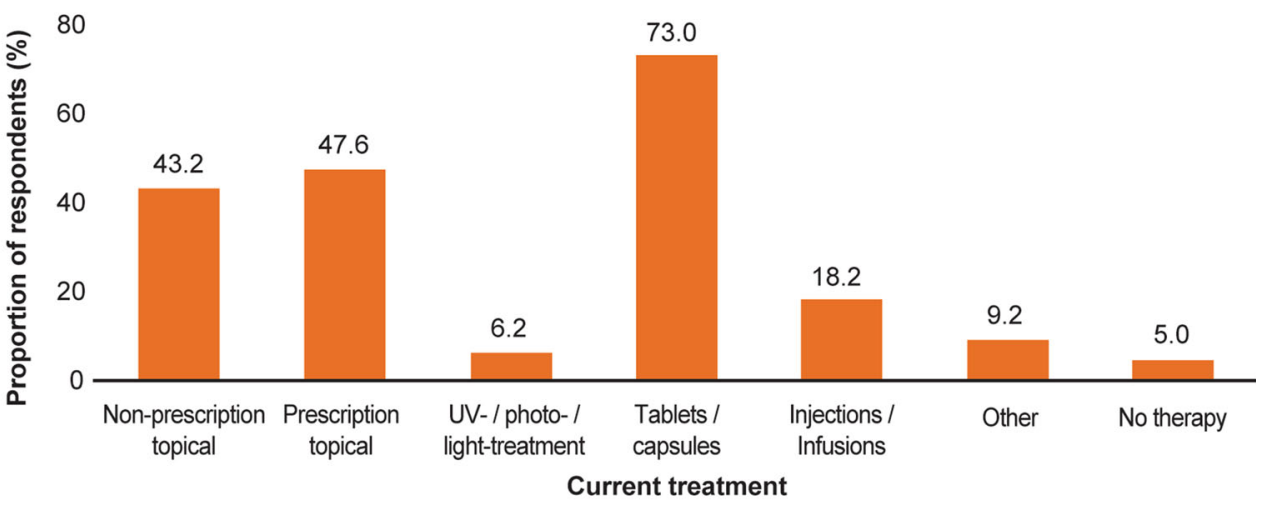

(c)

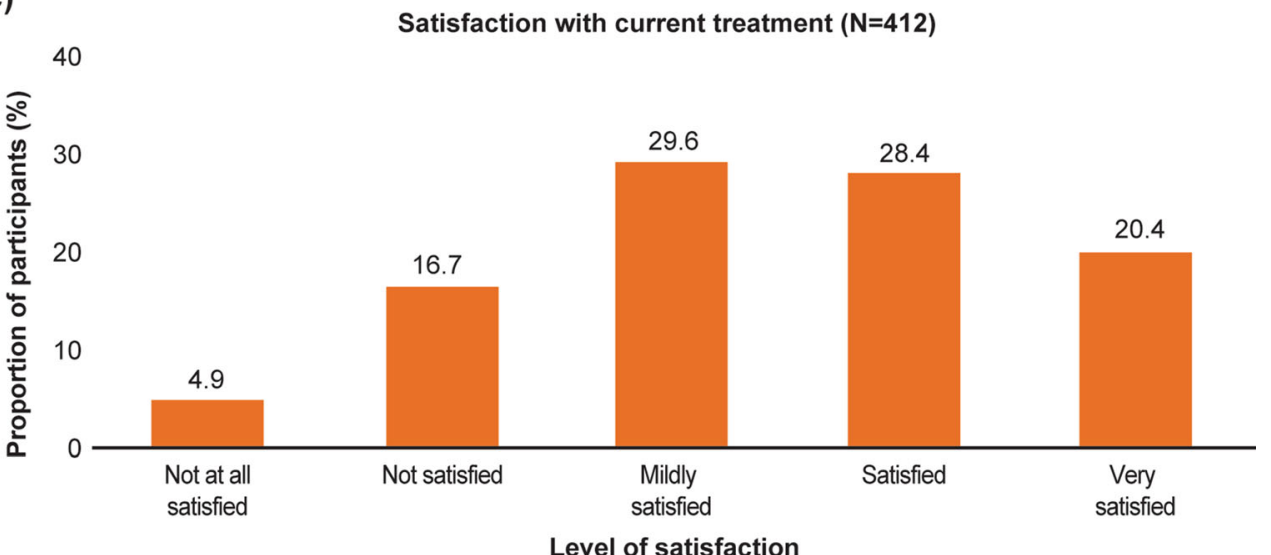

Fig. 4 Participants reported where they were currently being treated for their urticaria and if this treatment did or did not help $(n=412 ; \mathbf{a})$ and their current treatments using the pre-specified answers shown in the graph $(\mathbf{b})$ and their satisfaction with current treatment, using the prespecified answers in the graph $(n=412 ; \mathbf{c})$ 


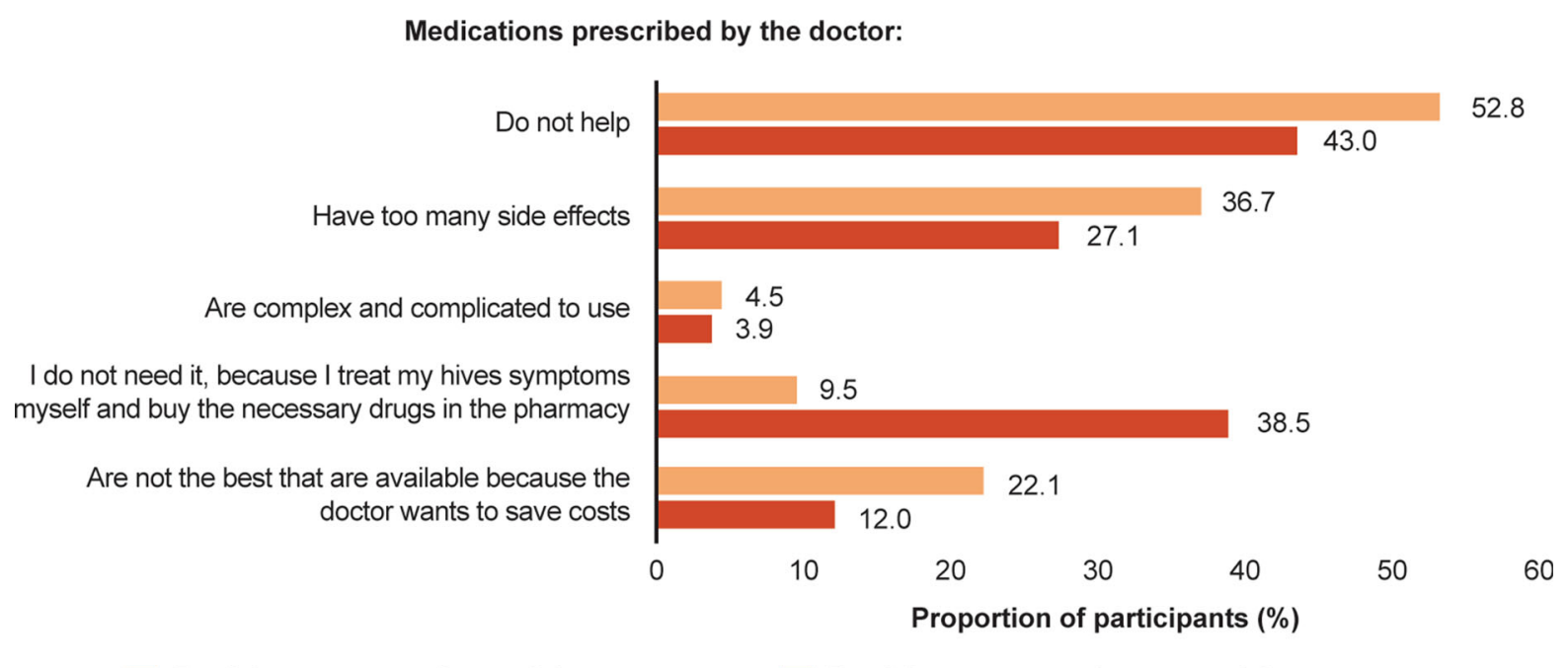

Participants currently receiving treatment

Participants currently not receiving treatment

Fig. 5 Patients recorded their reasons for dissatisfaction with medications (patients currently receiving treatment, $n=211$; patients currently not receiving treatment, $n=509$ )

satisfaction with medical care was analyzed in a large group of afflicted individuals, reaching even those not currently under the medical care of a physician for their CU. As noted in the literature, urticarial lesions may appear anywhere on the body [15], but there is little information on the areas most affected by wheals and angioedema. Participants in our survey reported that arms, legs, hands/fingers and chest/abdomen were the areas most affected by wheals, while hands/fingers, feet, head and arms were the predominant areas affected by angioedema. Many of these body areas are visible areas and difficult to conceal with clothing. Moreover, disease activity appears to peak during a significant time of an individual's life (mean age 33.4 years), a peak time for childbearing and high work productivity, with a high impact on QoL [16]. Involvement of the genitals or anal area are likely to be reported seldom as individuals may be embarrassed, but it may be very bothersome.

As expected, most participants (73\%) took oral medications (tablets or capsules) to treat their CU; this is likely to have included first-line $\mathrm{H}_{1}$ antihistamines, although medication was not further specified. Surprisingly, a high proportion of individuals were taking prescription topical $(47.6 \%)$ and non-prescription topical $(43.2 \%)$ medications. This finding was surprising as there are no approved topical treatments for $\mathrm{CU}$, although treatments may include prescriptions containing, for example, corticosteroids, antihistamines, polidocanol or local anesthetics, menthol, camphor or aqueous solutions with zinc or talcum in order to soothe pruritus [17].

The survey also revealed that many affected individuals were not being treated by a physician and tried to cope with their condition on their own.

Participants reported a high burden of disease, with many indicating that CU substantially affected their QoL. These findings are in line with previous studies detecting that patients with CU experience an underestimated emotional and psychological burden that impacts sleep and daily activities and restricts their ability to work and socialize [1, 3, 12, 18-20]. Most participants indicated that psychological factors, such as stress at work or in their private lives, triggered their disease or worsened their symptoms. Indeed, patients with CU have demonstrated significantly higher stress levels compared to controls [21], and stress has been shown to exacerbate urticarial wheals [22]. Our findings underline the relevance of stress management and coping mechanisms in the treatment of patients with CU. Participants said they avoided stressful 
situations for fear of triggering symptoms, while others reported restricting their social activities and modifying their daily lives, including their diets. Empowering the patient to have knowledge of their own potential triggers, such as stress or specific drugs, may help with individual treatment strategies, thereby improving CU symptoms and quality of life [23].

This study highlights the individual's perspective of seeming or feeling to be undertreated to a great extent, and the need for greater awareness of CU disease burden. Treatment options and/or escalation should be carefully addressed in order to achieve symptom control. However, interpretation of these results requires caution because patients may believe that their treatment is ineffective when their condition has not been cured within a few weeks of treatment; they might have stopped their medication due to inefficacy and/or inadequate adherence. Thus, communication between the physician and the patient about the nature of CSU, possible prolonged disease duration and treatment escalation options, must be discussed. Furthermore, patients unsatisfied with their treatment tend to be more willing to complete such web-based surveys.

It has been previously reported that high proportions of patients do not receive guideline-recommended treatments for CU despite having active disease [10]. This study highlights poor success rates of or disappointment with treatment in real-world situations as most participants felt that previous treatments did not help, and they were no longer under treatment.

Limitations of this survey include participant selection bias, as it was accessible only to those with internet access and promoted via personalized advertisements. Individuals who suffer most from their symptoms were probably more likely to see the advertisement, possibly due to their former internet search, and to participate in comparison to those whose symptoms were well-controlled; this could have potentially led to an overestimation of cases that were poorly controlled.

Indeed, a very high proportion of participants were female $(89 \%)$ and the mean age of 33.4 years was rather low for CU patients, similar to a previous online survey on $\mathrm{CU}$ in
Germany [24]. Both of these surveys had a similar design of recruiting individuals through online advertisements, which likely influenced the study population, resulting in the recruitment of participants of a younger mean age as compared to a clinical setting. Younger patients tend to be more prone to receiving information via social networks, such as Facebook. In the clinical studies ASSURE and AWARE, the mean age of CU patients was around 45 years and slightly over $70 \%$ of the study populations were female $[4,25]$. Female patients might be generally more in touch with their health and willing to seek out information on health conditions; consequently, female patients are more likely to respond to and participate in an online survey of this nature; this is a bias that is difficult to control for.

Although participant selection bias may be a limitation of a survey-based design, online surveys allow data collection from a large population of individuals, many of whom may not be receiving medical advice and thus would not be not accessible by other means, such as observational studies. Furthermore, the diagnosis of $\mathrm{CU}$ may not have been accurate in some cases due to the self-reported setting. We attempted to exclude participants with other dermatological conditions by asking, "Have you ever been diagnosed with chronic hives (urticaria) by a doctor? If no, then end the survey." If this question was answered accurately, the correct population should have been captured. In addition, CIndU, especially pressure- induced, might have been misinterpreted by the participants as angioedema. Pressure-induced urticaria is a frequent comorbidity of $\mathrm{CU}$ and can only be exactly diagnosed by physical testing. Online surveys are suitable for epidemiological studies that necessitate wide geographical coverage and a large sample size using a fast and cost-effective manner [26]. Finally, our internet survey was not validated. It was realized as a pilot project and resulted in an unexpected fast and high response rate of affected individuals. For more distinct data, validation of future online questionnaires would be beneficial. 


\section{CONCLUSIONS}

Overall, our findings contribute to a better understanding of $\mathrm{CU}$, the distribution of wheals and angioedema across the body and, especially, the perceived real-world burden of disease in affected individuals. The poor disease management and high psychological impact reported by participants in this survey support the need for a deeper understanding of the burden of disease in these patients and more insight in treatment options for CU in Germany. Furthermore, it is crucial to reach affected individuals who are currently not seeking medical advice in order to improve real-life patient care.

\section{ACKNOWLEDGEMENTS}

We thank the participants of the study.

Funding. This study and the Journal's rapid service fee were funded by Novartis Pharma GmbH, Germany.

Disclosures. Nicola Wagner received lecture and advisory board honoraria and a research grant from Novartis Pharma $\mathrm{GmbH}$, and participated in clinical trials with Novartis Pharma $\mathrm{GmbH}$. Alexander Zink has been an advisor for Novartis Pharma GmbH, received speaker's honoraria and unrestricted research grants from and participated in clinical trials with Novartis Pharma GmbH. Katharina Hell had a 1-day internship at Novartis Pharma GmbH with no payment. Maximilian C Schielein has received financial support for the presentation of scientific posters by Novartis Pharma GmbH. Maximilian Reinhardt, Katrin Romer, Elena Hillmann and Daniel Bäumer are employees of Novartis Pharma GmbH.

Medical Writing and Editorial Assistance. The authors thank Martin Wallace, PhD and Gillian Brodie, MSc (Novartis Pharmaceuticals, Ireland) for editorial and medical writing support, which was funded by Novartis Pharma $\mathrm{GmbH}$, in accordance with the Good Publication Practice (GPP3) guidelines (http://www. ismpp.org/gpp3).
Compliance with Ethics Guidelines. The study was notified retrospectively to the local ethics committee of the University of Erlangen. The study is exempt from institutional review board approval in line with national legislation in Germany. This study was performed in accordance with the Helsinki Declaration of 1964 and its later amendments. Participants provided consent to participate and data evaluation was performed anonymously.

Authorship. All named authors meet the International Committee of Medical Journal Editors (ICMJE) criteria for authorship for this article, take responsibility for the integrity of the work as a whole and have given their approval for this version to be published.

Author Contributions. NW, AZ, MCS, DB contributed to the concept and design of the study. All authors (NW, AZ, MCS, DB, KH, MR, $\mathrm{KR}, \mathrm{EH})$ contributed in drafting the manuscript.

Data Availability. The datasets generated during and/or analyzed during the current study are available from the corresponding author upon reasonable request.

Open Access. This article is licensed under a Creative Commons Attribution-NonCommercial 4.0 International License, which permits any non-commercial use, sharing, adaptation, distribution and reproduction in any medium or format, as long as you give appropriate credit to the original author(s) and the source, provide a link to the Creative Commons licence, and indicate if changes were made. The images or other third party material in this article are included in the article's Creative Commons licence, unless indicated otherwise in a credit line to the material. If material is not included in the article's Creative Commons licence and your intended use is not permitted by statutory regulation or exceeds the permitted use, you will need to obtain permission directly from the copyright holder. To view a copy of this licence, visit http://creativecommons.org/licenses/bync/4.0/. 


\section{REFERENCES}

1. Maurer M, Weller K, Bindslev-Jensen C, et al. Unmet clinical needs in chronic spontaneous urticarial. A GA(2)LEN task force report. Allergy. 2011;66:317-30.

2. Zuberbier T, Aberer W, Asero R, et al. The EAACI/ GA(2)LEN/EDF/WAO guideline for the definition, classification, diagnosis and management of urticaria. Allergy. 2018;73:1393-414.

3. Balp M, Chambenoit O, Chiva-Razavi S, et al. Work productivity and activity impairment among chronic spontaneous/idiopathic urticaria patients: results from the First International Burden of Illness Study (ASSURE-CSU). Value Health. 2015;18:A427.

4. Maurer M, Abuzakouk M, Berard F, et al. The burden of chronic spontaneous urticaria is substantial: real-world evidence from ASSURE-CSU. Allergy. 2017;72:2005-16.

5. Barbosa F, Freitas J, Barbosa A. Chronic idiopathic urticaria and anxiety symptoms. J Health Psychol. 2011;16:1038-47.

6. Staubach P, Dechene M, Metz M, et al. High prevalence of mental disorders and emotional distress in patients with chronic spontaneous urticaria. Acta Derm Venereol. 2011;91:557-61.

7. Staubach P, Eckhardt-Henn A, Dechene M, et al. Quality of life in patients with chronic urticaria is differentially impaired and determined by psychiatric comorbidity. Br J Dermatol. 2006;154:294-8.

8. Staubach P, Metz M, Chapman-Rothe N, et al. Effect of omalizumab on angioedema in H1-antihistamine-resistant chronic spontaneous urticaria patients: results from X-ACT, a randomized controlled trial. Allergy. 2016;71:1135-44.

9. Powell RJ, Leech SC, Till S, et al. BSACI guideline for the management of chronic urticaria and angioedema. Clin Exp Allergy. 2015;45:547-65.

10. Maurer M, Raap U, Staubach P, et al. Antihistamineresistant chronic spontaneous urticaria: 1-year data from the AWARE study. Clin Exp Allergy. 2019;49: 655-62.

11. Maurer M, Staubach P, Raap U, et al. H1-antihistamine-refractory chronic spontaneous urticaria: it's worse than we thought-first results of the multicenter real-life AWARE study. Clin Exp Allergy. 2017;47:684-92.

12. Weller K, Viehmann K, Brautigam M, et al. Costintensive, time-consuming, problematical? How physicians in private practice experience the care of urticaria patients. J Dtsch Dermatol Ges. 2012;10: 341-7.

13. Weller K, Groffik A, Church MK, et al. Development and validation of the Urticaria Control Test: a patient-reported outcome instrument for assessing urticaria control. J Allergy Clin Immunol. 2014;133: 1365-1372 e1361-1366.

14. Zuberbier T, Balke M, Worm M, Edenharter G, Maurer M. Epidemiology of urticaria: a representative cross-sectional population survey. Clin Exp Dermatol. 2010;35:869-73.

15. Sachdeva S, Gupta V, Amin SS, Tahseen M. Chronic urticaria. Indian J Dermatol. 2011;56:622-8.

16. Staubach $\mathrm{P}$, Metz $\mathrm{M}$, Chapman-Rothe $\mathrm{N}$, et al. Omalizumab rapidly improves angioedema-related quality of life in adult patients with chronic spontaneous urticaria: X-ACT study data. Allergy. 2018;73:576-84.

17. Weisshaar E, Florence WJCS, Dalgard J, et al. European S2k guideline on chronic pruritus. Acta Derm Venereol. 2019;99:469-506.

18. Lewis V, Finlay AY. 10 years experience of the Dermatology Life Quality Index (DLQI). J Investig Dermatol Symp Proc. 2004;9:169-80.

19. Delong LK, Culler SD, Saini SS, Beck LA, Chen SC. Annual direct and indirect health care costs of chronic idiopathic urticaria: a cost analysis of 50 nonimmunosuppressed patients. Arch Dermatol. 2008;144:35-9.

20. Tian H, Chambenoit O, Chiva-Razavi S, et al. Healthcare resource utilisation among chronic spontaneous/idiopathic urticaria patients-findings from the First International Burden of Illness Study (Assure-Csu). Value Health. 2015;18:A424.

21. Ograczyk-Piotrowska A, Gerlicz-Kowalczuk Z, Pietrzak A, Zalewska-Janowska AM. Stress, itch and quality of life in chronic urticaria females. Postepy Dermatol Alergol. 2018;35:156-60.

22. Conrad R, Geiser F, Haidl G, Hutmacher M, Liedtke $\mathrm{R}$, Wermter F. Relationship between anger and pruritus perception in patients with chronic idiopathic urticaria and psoriasis. J Eur Acad Dermatol Venereol. 2008;22:1062-9.

23. Curto-Barredo L, Pujol RM, Roura-Vives G, Gimenez-Arnau AM. Chronic urticaria phenotypes: clinical differences regarding triggers, activity, prognosis and therapeutic response. Eur J Dermatol. 2019;29:627-35.

24. Maurer M, Staubach P, Raap U, Richter-Huhn G, Baier-Ebert M, Chapman-Rothe N. ATTENTUS, a 
German online survey of patients with chronic urticaria highlighting the burden of disease, unmet needs and real-life clinical practice. Br J Dermatol. 2016;174:892-4.

25. Maurer M, Gimenez-Arnau A, Ensina LF, Chu CY, Jaumont X, Tassinari P. Chronic urticaria treatment patterns and changes in quality of life: AWARE study 2-year results. World Allergy Organ J. 2020;13:100460.

26. Arafa AE, Anzengruber F, Mostafa AM, Navarini AA. Perspectives of online surveys in dermatology. J Eur Acad Dermatol Venereol. 2019;33:511-20. 